\title{
ESTABELECIMENTO DOS PREÇOS NO BRASIL
}

\author{
PRICE SETTING IN BRAZIL
}

\section{FIJACIÓN DE LOS PRECIOS EN BRASIL}

\author{
Juliana Ventura Amaral \\ Doutora em Controladoria e Contabilidade \\ pela Universidade de São Paulo (USP), \\ Brasil \\ juliana.ventura.amaral@usp.br \\ Reinaldo Guerreiro \\ Doutor em Controladoria e Contabilidade \\ pela Universidade de São Paulo (USP), \\ Brasil \\ reiguerr@usp.br
}

\author{
Contextus \\ ISSNe 2178-9258 \\ Organização: Comitê Científico Interinstitucional \\ Editor Científico: Diego de Queiroz Machado \\ Editor Executivo: Carlos Daniel Andrade \\ Avaliação: double blind review pelo SEER/OJS \\ Recebido em 01/11/2017 \\ Aceito em 27/04/2018 \\ $2^{\text {a }}$ versão aceita em 08/05/2018
}

\section{RESUMO}

Os levantamentos sobre como se estabelecem os preços no Brasil são limitados, pois se restringem a regiões específicas e a amostras pequenas. Nesse sentido, buscou-se apresentar neste artigo os resultados de uma pesquisa empírica atualizada e abrangente sobre o estabelecimento dos preços no Brasil. Com base em 380 respostas de empresas de variados portes das cinco regiões brasileiras, identificou-se que os preços são definidos, principalmente, por gestores homens do departamento de vendas. Tanto as empresas formadoras quanto as tomadoras de preços usam intensamente informações de custos e têm a combinação custos mais margem como a forma predominante do processo. Constatou-se ainda que, apesar da dominância, a fórmula custos mais margem não configura necessariamente a essência da determinação dos preços, pois a margem pode viabilizar a incorporação de informações da concorrência e do valor.

Palavras-chave: Preços; Estabelecimento dos Preços; Brasil; Custos; Custo mais margem.

\section{ABSTRACT}

Surveys assessing price setting behavior in Brazil have been limited due to the exploration of restricted regions and due to the small size of the samples. In this sense, our study was specifically concerned with providing a comprehensive and updated view about pricing practices in Brazil. Our study was conducted based on a survey with 380 pricing professionals who work in large and small firms from the five Brazilian regions. The results showed that, in Brazil, prices are mainly set by male managers of the sales department. In addition, results provided some support for revealing that cost information is intensively used and cost-plus is the predominant shape of the process for both price makers and price takers. Despite this predominance, it is noteworthy pointing that cost-plus formulas do not necessarily lead to a pricing essence, because margin may connect costs to pieces of information of competitors and value.

Keywords: Prices; Price Setting; Brazil; Costs; Cost Plus margin.

\section{RESUMEN}

Los levantamientos acerca de cómo los precios son fijados en Brasil son limitados, ya que son restringidos a regiones específicas y compuestos por pequeñas amuestras. Así, este artículo buscó presentar los resultados de una pesquisa empírica actual e detallada acerca de la fijación de precios en Brasil. Con base en 380 respuestas de empresas de variados portes de las cinco regiones de Brasil, los resultados han revelado que los precios son fijados por gestores hombres de la sección de ventas. Tanto los formadores cuanto los tomadores de precios usan con intensidad las informaciones de costos e tienen la combinación costo más margen como la forma predominante del proceso. Los resultados también revelan que, mientras dominante, la formula costo más margen no configura de modo estricto la esencia de la fijación de precios, ya que la margen puede viabilizar la incorporación de informaciones de la competencia y del valor.

Palabras clave: Precios; Fijación de Precios; Brasil; Costos; Costo más margen. 


\section{INTRODUÇÃO}

Ao se realizarem buscas sobre estabelecimento de preços em variadas bases científicas com visibilidade internacional, tem-se uma constatação surpreendente: apenas uma pesquisa se refere ao Brasil: Braga et al. (2012), sobre a definição dos preços em 8 indústrias conserveiras de pequeno e médio porte da região de Pelotas (Rio Grande do Sul). Isso significa que esse é o único trabalho que pesquisadores internacionais tendem a tomar como base para inferir como se determinam os preços no Brasil. Para pesquisadores nacionais, a situação é um tanto distinta, sendo possível encontrar 20 trabalhos sobre o tema, incluindo versão de Braga et al. (2012).

O problema é que os pesquisadores locais ainda não articularam nem consolidaram de forma estruturada os resultados dos estudos prévios para estabelecer um panorama geral do que se sabe e do que não se sabe sobre a determinação dos preços no Brasil. Talvez, por esse motivo, não se tenha ainda percebido quão limitada é a ciência brasileira sobre o assunto.

Ora, compreender o estabelecimento dos preços em empresas localizadas no Brasil é relevante porque o país, além de emergente, tem uma importância expressiva na economia mundial. Ainda que exposto a uma crise econômica, não se pode deixar de reconhecer que o Brasil é membro do BRICS - grupo de países emergentes formado por Brasil, Rússia, Índia, China e África do Sul - e é o maior país da América Latina. Além disso, em ranking do IBGE e do Fundo Monetário Internacional, o Brasil ocupa o $9^{\circ}$ lugar entre as maiores economias do planeta (NAKAGAWA, 2016).

Diante dessas observações, busca-se neste artigo revisar de maneira organizada os prévios estudos empíricos nacionais e, assim, identificar as principais limitações sobre o conhecimento do tema. Com isso, põe-se o objetivo de realizar uma nova pesquisa empírica que supere tais limitações e descreva de forma abrangente como os preços são estabelecidos no Brasil.

\section{REVISÃO SOBRE O ESTABELECIMENTO DOS PREÇOS NO BRASIL}

Para localizar estudos sobre o estabelecimento dos preços no Brasil, fizeram-se buscas em bases científicas e em sites de revistas e de congressos brasileiros. Procurou-se 
especialmente acessar os sites de revistas da área "Administração, Ciências Contábeis e Turismo" classificadas até o extrato B5 pela Coordenação de Aperfeiçoamento de Pessoal de Nível Superior (CAPES, 2016) e os sites dos eventos da mesma área que já foram classificados como E1 (CAPES, 2009). Vale mencionar que, além dos 20 levantamentos relacionados nesta seção, foram localizados diversos estudos de casos, aqui não expostos por priorizarem a exposição específica das entidades estudadas, sem, pelo menos, descreverem um panorama geral da definição dos preços na região investigada.

O primeiro trabalho brasileiro localizado nas bases consultadas foi o de Mello (2000). Tal trabalho inspirou-se na pesquisa de Hall e Hitch (1939) e implicou a remessa de um questionário para empresas industriais de pequeno porte do município gaúcho de Santa Maria e para empresas de grande porte localizadas em qualquer município gaúcho. Mello (2000) obteve 23 respostas e reportou que os preços eram estabelecidos prioritariamente com base na soma de uma margem aos custos. Apesar disso, segundo ele, a demanda e, sobretudo, os preços dos concorrentes tinham papel relevante para determinar os preços. Ele citou o depoimento de um empresário para quem "o mercado é que determina as margens. Como o mercado é de alto giro, as margens são pequenas, definir margens que não acontecem, não interessa" (p. 34).

Na sequência, encontrou-se o estudo de Barbosa (2003), que investigou o estabelecimento dos preços em empresas industriais e de construção de diversos portes. $\mathrm{O}$ questionário foi remetido mediante duas estratégias: (1) entrevistas pessoais a empresas da região metropolitana de Recife; e (2) envio de mensagens eletrônicas para representantes de empresas de todo o país. 53 respostas foram obtidas com base na primeira estratégia e 31 com base na segunda estratégia, mas 3 questionários tiveram de ser excluídos. Ao questionar a fórmula usada para estabelecer os preços, Barbosa (2003) constatou que a maioria das empresas combinava informações de custos a informações de mercado. A autora também observou que as empresas enfatizavam o uso do custo total, em vez do custo variável, mas, ainda assim, definiam preços coerentes com aqueles disponíveis no mercado.

Para o ano seguinte, encontrou-se o estudo de Rosadas e Macedo (2004). Os autores averiguaram empresas de pequeno porte que comercializavam materiais de construção em bairros do subúrbio carioca. Conseguiram obter respostas de 37 empresas. Como principais achados, destacaram a nítida predominância dos custos mais margem. Também observaram que a margem era formada quer pela crença de que um determinado preço final era adequado, 
quer por informações advindas dos fornecedores dos produtos. A margem colocada variava de $8 \%$ a $40 \%$.

Em seguida, achou-se a pesquisa de Silva e Santos (2005), concentrada na definição dos preços em indústrias de pequeno porte, localizadas na região de Ribeirão Preto, que atuavam com exportações de equipamentos médico-hospitalares e odontológicos. Com 4 respostas obtidas, os autores constataram serem os custos a principal base para definir preços. Especificamente, eles observaram que uma margem simples era colocada sobre os custos, espelhando o lucro desejado.

Depois, localizou-se a pesquisa de Dias, Carvalho e Cogan (2006), sobre lojas do setor do vestuário no Shopping Center Rio Sul, localizado na capital fluminense. Os autores conseguiram obter a participação de 19 empresas e detectaram que todas determinavam o preço da mesma maneira, isto é, todas somavam uma margem ao custo do produto. Eles relataram que a simplicidade da combinação dos custos à margem aliada ao atendimento das expectativas de retorno dos lojistas explicava o censo encontrado.

Referente ao mesmo ano, o estudo de Machado e Souza (2006) contou com a participação de 9 indústrias conserveiras do Rio Grande do Sul de médio e grande porte. Os autores identificaram que $100 \%$ das empresas calculavam os preços com base nos custos mais margem. No entanto, apenas 33\% cobravam necessariamente o preço calculado porque não dependiam dos preços dos concorrentes, tinham clientes extremamente fiéis, ofereciam produtos de alta qualidade e ofertavam um prazo de pagamento interessante. Nas demais empresas (67\%), considerava-se o preço calculado originalmente apenas como referência ou ponto de partida para a negociação. $89 \%$ das empresas afirmaram reduzir a margem quando ela orientava a preços maiores do que os concorrentes.

Continuando com 2006, foi encontrado o trabalho de Machado, Machado e Holanda (2006), investigando a deliberação das tarifas em hotéis de João Pessoa. Os autores entrevistaram representantes de 31 hotéis de variados portes e concluíram que a maior parte (71\%) definia os preços com base em informações de custos e de mercado. Na sequência, apareciam os hotéis que estabeleciam os preços pautados unicamente nos custos $(12,9 \%)$ ou unicamente no mercado $(9,7 \%)$. Os autores também ressaltaram que 64,5\% dos hotéis consideravam as informações de custos muito úteis para as decisões de preços e que, enquanto $54,8 \%$ dos hotéis priorizavam o uso dos custos totais, outros $25,8 \%$ privilegiavam os custos variáveis. 
Para o ano seguinte, localizou-se a pesquisa de Almeida e Santos (2007), cuja amostra se compunha de 14 indústrias paranaenses de médio e grande porte. Os autores detectaram que, ao definir os preços, as firmas priorizavam informações de mercado, sobretudo de elasticidade e de economia. Informações de custos apareciam na sequência, pois os conceitos de custeio variável e de margem de contribuição eram levados em consideração.

Continuando a exploração de 2007, o estudo de Callado et al. (2007) concentrou-se em averiguar como as agroindústrias da Paraíba definiam os preços. Os autores conseguiram obter 20 respostas com as quais detectaram que a ampla maioria das empresas (70\%) estabelecia os preços sobrepondo uma margem aos custos de fabricação. Na sequência, apareciam os preços formados caso a caso com cada cliente (20\%) e os preços definidos com a sobreposição de uma margem unicamente ao custo das matérias primas (5\%).

Ainda para 2007, localizou-se a pesquisa de Cogan et al. (2007), sobre as micro- e pequenas empresas comerciais dos municípios de Guapimirim e Teresópolis, no estado do Rio de Janeiro. Os autores obtiveram 19 respostas e constataram que a maioria das firmas definia os preços com base nos custos mais margem (36\%). Na sequência, apareciam os preços de acordo com os preços da concorrência (32\%), com os custos de compras mais despesas (18\%) e com os custos de compras apenas (14\%). Cogan et al. (2007) também observaram que $65 \%$ dos respondentes definiam a margem com base na sua própria experiência. Na sequência, apareciam os respondentes que faziam essa definição com base em relatórios contábeis (17\%), no mercado (9\%) e no conselho de outros profissionais da empresa, como do contador $(9 \%)$.

Para o mesmo ano, também se encontrou o estudo de Lima, Ferrarezi e Smith (2007), voltado a explorar o papel dos custos no estabelecimento dos preços em indústrias metalúrgicas de Franca, cidade do interior paulista. Os autores realizaram 15 entrevistas com representantes de empresas de micro- e de pequeno porte, mediante as quais concluíram que se dava ênfase às informações de custos apuradas pelos métodos de custeio pleno e por absorção. 60\% das empresas usavam informações apuradas por esses custeios. Vale, entretanto, esclarecer que não averiguaram se as empresas utilizavam outros tipos de informações além daquelas relativas a custos.

Em seguida, achou-se o trabalho de Hamann et al. (2010), voltado a empresas agroindustriais familiares da região de Planaltina (DF). Os autores aplicaram um questionário a produtores familiares da referida região, mas não mencionaram a quantidade de empresas 
para as quais se encaminhou o questionário, tampouco quantas respostas foram obtidas. Eles concluíram que, para definirem os preços, as agroindústrias familiares de Planaltina enfatizavam as informações de preços de mercado (59\%). Em segundo lugar, apareciam as empresas que determinavam os preços com base nos custos (29\%) e com base na deliberação de cooperativas (12\%). Os autores também observaram que a margem era definida principalmente como uma função dos gastos (41\%), ou seja, aparentemente para cobrir todos os gastos.

Ainda averiguando 2010, localizou-se o estudo de Machado, Fiorentin e Scarpin (2010), voltado a indústrias metalúrgicas de médio e grande porte de Santa Catarina. Com base em respostas obtidas de 15 empresas, os autores identificaram que os custos dos produtos compunham a informação considerada pelas empresas como a mais importante no estabelecimento dos preços. No entanto, os preços calculados com base neles, antes de serem de fato cobrados, eram comparados aos preços do mercado. Caso o preço indicado pelo cálculo fosse maior que os preços dos concorrentes, as empresas revisavam os custos. Os autores também detectaram que, na maior parte das empresas $(86,68 \%)$, o custo usado no estabelecimento dos preços incluía todos os custos de produção, os impostos sobre vendas e as despesas com vendas. A margem de lucro bruto incidia normalmente na forma percentual.

Logo depois, achou-se a pesquisa de Alves, Varotto e Gonçalves (2012), empresas paulistanas de varejo de variados portes. Os autores obtiveram 300 respostas e concluíram que os métodos baseados nos custos eram empregados com mais frequência. Afirmaram que a simplicidade desses métodos poderia explicar essa frequência. Entretanto, os autores, vale esclarecer, extraíram essas conclusões sem de fato investigarem os tipos de informações usados no processo de definir os preços, ou seja, a argumentação se pautou arbitrariamente pela classificação que haviam feito dos métodos. Por exemplo, preços premium, segundo eles, caracterizavam a aplicação de métodos baseados nos custos. Logo, deve-se tomar cautela ao interpretar os resultados.

Ainda explorando 2012, o estudo de Braga et al. (2012) investigou o estabelecimento dos preços em indústrias conserveiras de pequeno e médio porte da região gaúcha de Pelotas. Com base em 8 respostas, os autores detectaram que a maioria (75\%) estabelecia os preços somando uma margem aos custos. As outras empresas (25\%) definiam os preços de acordo com a média do mercado. Braga et al. (2012) ressaltaram que, mesmo quando o preço era tomado do mercado, os custos mais margem podiam ser usados para avaliar a lucratividade. 
Os autores também observaram que o uso do custo total era priorizado por 5 empresas, enquanto o uso do custeio variável era priorizado por 3 empresas.

Para o mesmo ano, localizou-se a pesquisa de Canever et al. (2012), que investigou as maiores empresas industriais de Santa Catarina. As 12 respostas foram usadas para concluir que a maior parte das empresas (67\%) definia os preços em função do que os autores nomearam como "métodos mistos", isto é, o uso combinado de informações de custos, da concorrência e do valor. Na sequência, apareciam as empresas que determinavam os preços exclusivamente com base nos custos $(16,5 \%)$ e que unicamente tomavam o preço no mercado $(16,5 \%)$. Canever et al. (2012) também constataram que se empregava intensivamente o custo apurado pelo custeio por absorção.

Para o ano seguinte, o trabalho de Dallabona et al. (2013) debruçou-se sobre honorários nos escritórios de contabilidade de Tangará da Serra (Mato Grosso). 28 respostas subsidiaram a conclusão de que a principal informação considerada para definir os preços dos honorários era o tempo consumido para realizar o trabalho e, consequentemente, seu custo. $\mathrm{Na}$ sequência, tanto os custos quanto o valor revelaram influência de informações como o grau de dificuldade e as características do serviço.

Ainda investigando 2013, Queiroz et al. (2013) pesquisaram microempresas de artigos turísticos localizadas em Fortaleza, capital cearense, e em Mindelo (Cabo Verde). Ao todo, eles obtiveram 30 respostas, sendo 15 de cada local. Conforme os autores, os preços eram estabelecidos, em ambas as cidades, em função de algum mecanismo de custos mais margem. Enquanto, em Fortaleza, a base principal era o custo de aquisição da mercadoria mais a margem (46\%), a base em Mindelo era, sobretudo, o custo de produção total médio mais margem. Segundo Queiroz et al. (2013) também constataram, aspectos como a variação na demanda, a alteração nos preços dos concorrentes e a nacionalidade dos clientes podiam, em algumas circunstâncias, modificar os preços colocados. Por exemplo, preços mais elevados eram propostos para clientes internacionais.

Na sequência, achou-se a pesquisa de Kruger et al. (2014), que investigou 150 estabelecimentos rurais do município de Erval Grande (Rio Grande do Sul). Os autores concluíram que os preços se estabeleciam basicamente em função de informações do mercado, especialmente referentes tanto ao preço oferecido pela cooperativa ou empresa compradora, quanto ao preço do mercado. 
Depois, finalmente, encontrou-se o estudo de Rocha e Leal (2015), sobre pequenas empresas comerciais de Uberlândia (MG). Os autores obtiveram 48 respostas, com as quais detectaram tanto o uso conjunto de informações do preço de mercado e dos custos $(60,4 \%)$, quanto a pequena utilização de uma margem de lucro única $(12,5 \%)$.

A Tabela 1 resume os estudos localizados sobre o estabelecimento dos preços no Brasil.

Tabela 1 - Sumário dos estudos sobre o estabelecimento dos preços no Brasil

\begin{tabular}{|c|c|c|c|c|c|}
\hline ESTUDO & LOCAL & Amostra & PORTE & RAMO & $\begin{array}{l}\text { PRINCIPAL } \\
\text { CONCLUSÃo }\end{array}$ \\
\hline $\begin{array}{l}\text { Mello } \\
(2000)\end{array}$ & $\begin{array}{l}\text { Rio Grande } \\
\text { do Sul }\end{array}$ & 23 & $\begin{array}{l}\text { Pequenas e } \\
\text { grandes } \\
\text { empresas }\end{array}$ & Indústria & 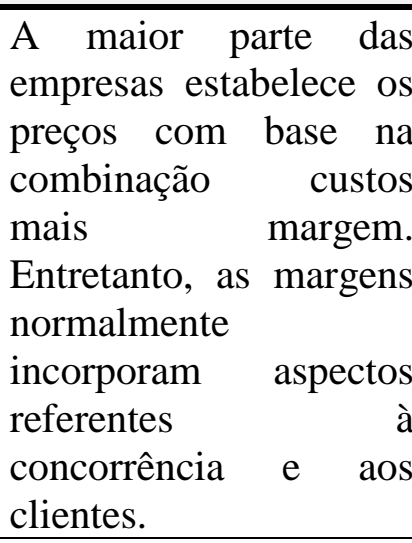 \\
\hline $\begin{array}{l}\text { Barbosa } \\
(2003)\end{array}$ & \begin{tabular}{|l|} 
Ênfase na \\
região \\
metropolitana \\
do Recife \\
$(\mathrm{PE})$ \\
\end{tabular} & 81 & $\begin{array}{l}\text { Variados } \\
\text { portes }\end{array}$ & $\begin{array}{l}\text { Indústria e } \\
\text { construção }\end{array}$ & $\begin{array}{l}\text { A maior parte das } \\
\text { empresas estabelece os } \\
\text { preços com base no uso } \\
\text { de informações de } \\
\text { custos e de mercado. }\end{array}$ \\
\hline $\begin{array}{l}\text { Rosadas e } \\
\text { Macedo } \\
(2004)\end{array}$ & $\begin{array}{l}\text { Rio de } \\
\text { Janeiro }(\mathrm{RJ})\end{array}$ & 37 & $\begin{array}{l}\text { Pequenas } \\
\text { empresas }\end{array}$ & Comércio & $\begin{array}{l}\text { A maior parte das } \\
\text { empresas estabelece os } \\
\text { preços com base na } \\
\text { combinação custos } \\
\text { mais margem. } \\
\text { Informações advindas } \\
\text { dos fornecedores são } \\
\text { utilizadas para } \\
\text { definição das margens. }\end{array}$ \\
\hline $\begin{array}{l}\text { Silva e } \\
\text { Santos } \\
(2005)\end{array}$ & $\begin{array}{l}\text { Ribeirão } \\
\text { Preto (SP) }\end{array}$ & 4 & $\begin{array}{l}\text { Pequenas } \\
\text { empresas }\end{array}$ & Indústria & $\begin{array}{l}\text { A maior parte das } \\
\text { empresas estabelece os } \\
\text { preços com base na } \\
\text { combinação custos } \\
\text { mais margem. }\end{array}$ \\
\hline $\begin{array}{l}\text { Dias, } \\
\text { Carvalho } \\
\text { e Cogan } \\
(2006)\end{array}$ & $\begin{array}{l}\text { Rio de } \\
\text { Janeiro (RJ) }\end{array}$ & 19 & $\begin{array}{l}\text { Não } \\
\text { mencionado }\end{array}$ & Comércio & $\begin{array}{lr}\text { Todas as empresas } \\
\text { estabelecem os } & \text { preços } \\
\text { com base } & \text { na } \\
\text { combinação } & \text { custos } \\
\text { mais margem. } & \end{array}$ \\
\hline
\end{tabular}




\begin{tabular}{|c|c|c|c|c|c|}
\hline $\begin{array}{l}\text { Machado } \\
\text { e Souza } \\
(2006)\end{array}$ & $\begin{array}{l}\text { Rio Grande } \\
\text { do Sul }\end{array}$ & 9 & $\begin{array}{l}\text { Médias e } \\
\text { grandes } \\
\text { empresas }\end{array}$ & Indústria & $\begin{array}{l}\text { Todas as empresas } \\
\text { estabelecem os preços } \\
\text { com base na } \\
\text { combinação custos } \\
\text { mais margem. } \\
\text { Entretanto, os preços } \\
\text { baseados estritamente } \\
\text { na combinação são } \\
\text { exceções e não regras; } \\
\text { dependendo dos preços } \\
\text { dos concorrentes, a } \\
\text { margem é modificada. }\end{array}$ \\
\hline $\begin{array}{l}\text { Machado, } \\
\text { Machado } \\
\text { e Holanda } \\
(2006)\end{array}$ & $\begin{array}{l}\text { João Pessoa } \\
\text { (PB) }\end{array}$ & 31 & $\begin{array}{l}\text { Variados } \\
\text { portes }\end{array}$ & Serviços & $\begin{array}{l}\text { A maior parte das } \\
\text { empresas estabelece os } \\
\text { preços com base no uso } \\
\text { de informações de } \\
\text { custos e de mercado. }\end{array}$ \\
\hline $\begin{array}{l}\text { Almeida e } \\
\text { Santos } \\
(2007)\end{array}$ & Paraná & 14 & $\begin{array}{l}\text { Médias e } \\
\text { grandes } \\
\text { empresas }\end{array}$ & Indústria & $\begin{array}{l}\text { A maior parte das } \\
\text { empresas estabelece os } \\
\text { preços com base em } \\
\text { informações } \\
\text { mercado. Ainda assim, } \\
\text { as empresas usam } \\
\text { informações de custos } \\
\text { no processo de } \\
\text { definição dos preços. }\end{array}$ \\
\hline $\begin{array}{l}\text { Callado et } \\
\text { al. (2007) }\end{array}$ & Paraíba & 20 & $\begin{array}{l}\text { Não } \\
\text { mencionado }\end{array}$ & Indústria & $\begin{array}{l}\text { A maior parte das } \\
\text { empresas estabelece os } \\
\text { preços com base na } \\
\text { combinação custos } \\
\text { mais margem. }\end{array}$ \\
\hline $\begin{array}{l}\text { Cogan et } \\
\text { al. }(2007)\end{array}$ & $\begin{array}{l}\text { Guapimirim } \\
\text { e Teresópolis } \\
(\mathrm{RJ})\end{array}$ & 19 & $\begin{array}{l}\text { Micro- e } \\
\text { pequenas } \\
\text { empresas }\end{array}$ & Comércio & $\begin{array}{l}\text { A maior parte das } \\
\text { empresas estabelece os } \\
\text { preços com base na } \\
\text { combinação custos } \\
\text { mais margem. }\end{array}$ \\
\hline $\begin{array}{l}\text { Lima, } \\
\text { Ferrarezi } \\
\text { e Smith } \\
(2007)\end{array}$ & Franca (SP) & 15 & $\begin{array}{l}\text { Micro- e } \\
\text { pequenas } \\
\text { empresas }\end{array}$ & Indústria & $\begin{array}{l}\text { A maior parte das } \\
\text { empresas estabelece os } \\
\text { preços com base em } \\
\text { custos apurados pelos } \\
\text { custeio pleno ou por } \\
\text { absorção. }\end{array}$ \\
\hline $\begin{array}{l}\text { Hamann } \\
\text { et al. } \\
(2010)\end{array}$ & $\begin{array}{l}\text { Planaltina } \\
\text { (DF) }\end{array}$ & $\begin{array}{l}\text { Não } \\
\text { mencionado }\end{array}$ & $\begin{array}{l}\text { Pequenas } \\
\text { empresas }\end{array}$ & Indústria & $\begin{array}{l}\text { A maior parte das } \\
\text { empresas estabelece } \\
\text { seus preços com base } \\
\text { nos de mercado. }\end{array}$ \\
\hline
\end{tabular}


(CONTINUAÇÃO)

\begin{tabular}{|c|c|c|c|c|c|}
\hline $\begin{array}{l}\text { Machado, } \\
\text { Fiorentin } \\
\text { e Scarpin } \\
(2010)\end{array}$ & $\begin{array}{l}\text { Santa } \\
\text { Catarina }\end{array}$ & 15 & $\begin{array}{l}\text { Médias e } \\
\text { grandes } \\
\text { empresas }\end{array}$ & Indústria & $\begin{array}{l}\text { A maior parte das } \\
\text { empresas estabelece os } \\
\text { preços com base na } \\
\text { combinação custos } \\
\text { mais margem. } \\
\text { Entretanto, antes de } \\
\text { serem de fato cobrados, } \\
\text { os preços são } \\
\text { comparados aos preços } \\
\text { do mercado. }\end{array}$ \\
\hline $\begin{array}{l}\text { Alves, } \\
\text { Varotto e } \\
\text { Gonçalves } \\
(2012)\end{array}$ & $\begin{array}{l}\text { São Paulo } \\
\text { (SP) }\end{array}$ & 300 & $\begin{array}{l}\text { Variados } \\
\text { portes }\end{array}$ & Comércio & $\begin{array}{l}\text { A maior parte das } \\
\text { empresas estabelece os } \\
\text { preços com base em } \\
\text { estratégias baseadas nos } \\
\text { custos. }\end{array}$ \\
\hline $\begin{array}{l}\text { Braga et } \\
\text { al. (2012) }\end{array}$ & Pelotas (RS) & 8 & $\begin{array}{l}\text { Pequenas e } \\
\text { médias } \\
\text { empresas }\end{array}$ & Indústria & $\begin{array}{l}\text { A maior parte das } \\
\text { empresas estabelece os } \\
\text { preços com base na } \\
\text { combinação custos } \\
\text { mais margem. Em } \\
\text { alguns casos, a } \\
\text { combinação é usada } \\
\text { apenas para avaliação } \\
\text { da lucratividade, pois o } \\
\text { preço precisa ser } \\
\text { tomado do mercado. }\end{array}$ \\
\hline $\begin{array}{l}\text { Canever } \\
\text { et al. } \\
(2012)\end{array}$ & $\begin{array}{l}\text { Santa } \\
\text { Catarina }\end{array}$ & 12 & $\begin{array}{l}\text { Grandes } \\
\text { empresas }\end{array}$ & Indústria & $\begin{array}{l}\text { A maior parte das } \\
\text { empresas estabelece os } \\
\text { preços com base no uso } \\
\text { de informações de } \\
\text { custos, da concorrência } \\
\text { e do valor. }\end{array}$ \\
\hline $\begin{array}{l}\text { Dallabona } \\
\text { et al. } \\
(2013)\end{array}$ & $\begin{array}{l}\text { Tangará da } \\
\text { Serra (MT) }\end{array}$ & 28 & $\begin{array}{l}\text { Não } \\
\text { mencionado }\end{array}$ & Serviço & $\begin{array}{lr}\text { A maior parte das } \\
\text { empresas estabelece os } \\
\text { preços considerando o } \\
\text { tempo que } & \text { será } \\
\text { consumido } & \text { na } \\
\text { realização } & \text { dos } \\
\text { trabalhos. } & \end{array}$ \\
\hline
\end{tabular}




\section{(CONTINUAÇÃO)}

\begin{tabular}{|c|c|c|c|c|c|}
\hline $\begin{array}{l}\text { Queiroz et } \\
\text { al. (2013) }\end{array}$ & $\begin{array}{l}\text { Fortaleza } \\
\text { (CE) e } \\
\text { Mindelo } \\
\text { (Cabo Verde) }\end{array}$ & 30 & Microempresas & $\begin{array}{l}\text { Indústria e } \\
\text { comércio }\end{array}$ & $\begin{array}{lrr}\text { A maior parte } & \text { das } \\
\text { empresas estabelece os } \\
\text { preços com base } & \text { na } \\
\text { combinação } & \text { custos } \\
\text { mais } & \text { margem. } & \text { A } \\
\text { demanda, os preços dos } \\
\text { concorrentes } & \text { e } & \text { as } \\
\text { características } & \text { dos } \\
\text { clientes } & \text { podem } \\
\text { conduzir a } & \text { mudanças } \\
\text { em relação aos } & \text { preços } \\
\text { propostos } & \text { pela } \\
\text { combinação. } & \\
\end{array}$ \\
\hline $\begin{array}{l}\text { Kruger et } \\
\text { al. }(2014)\end{array}$ & $\begin{array}{l}\text { Erval Grande } \\
(\mathrm{RS})\end{array}$ & 150 & $\begin{array}{l}\text { Variados } \\
\text { portes }\end{array}$ & Rural & $\begin{array}{l}\text { A maior parte das } \\
\text { empresas estabelece os } \\
\text { preços com base em } \\
\text { informações } \\
\text { mercado. }\end{array}$ \\
\hline $\begin{array}{l}\text { Rocha e } \\
\text { Leal } \\
(2015)\end{array}$ & $\begin{array}{l}\text { Uberlândia } \\
(\mathrm{MG})\end{array}$ & 48 & $\begin{array}{l}\text { Pequenas } \\
\text { empresas }\end{array}$ & Comércio & $\begin{array}{l}\text { A maior parte das } \\
\text { empresas estabelece os } \\
\text { preços com base no uso } \\
\text { de informações de } \\
\text { custos e de mercado. }\end{array}$ \\
\hline
\end{tabular}

Fonte: elaboração própria (2017).

Por meio da análise da Tabela 1, pode-se perceber cinco limitações nos trabalhos brasileiros prévios sobre estabelecimento de preços:

1) Todas as pesquisas, sem exceção, têm uma característica diferente da maior parte das pesquisas publicadas em outros países: abordam regiões geográficas bastante restritas, em vez de explorarem a realidade do país como um todo. As conclusões apresentadas ou se referem à realidade constatada em empresas de uma determinada cidade ou demonstram os achados de empresas de diferentes cidades de um único estado. Barbosa (2003) até tentou aplicar um questionário sem a restrição de região, contudo acabou tendo de completar a pesquisa com entrevistas limitadas a empresas da região metropolitana do Recife (PE);

2) Os estudos normalmente investigam as regiões sudeste e sul do Brasil, sendo poucos os dedicados a explorar as outras regiões. Constatou-se que $70 \%$ dos trabalhos se concentram no eixo sudeste-sul e somente $30 \%$ investigam empresas do nordeste e do centro-oeste. Nenhum trabalho com empresas da região norte foi encontrado; 
3) Também diferentemente dos trabalhos internacionais, que usualmente contemplam robustas bases amostrais, os brasileiros lidam com amostras bastante pequenas, o que tende a limitar a significância estatística dos resultados. Dos 20 trabalhos encontrados, 16 têm amostra inferior a 50 empresas, 10 deles chegando a cobrir no máximo 20 componentes;

4) As pesquisas priorizam explorar a definição de preços em firmas de pequeno porte. Somente 4 dos 20 estudos nacionais dedicam-se a investigar a realidade das grandes empresas;

5) Os trabalhos enfatizam a forma de estabelecer preços e chegam à conclusão predominante de que estes são definidos mediante a combinação dos custos à margem. Dos 20 estudos localizados, essa foi a constatação de 11, ou seja, 55\%. A maioria dos trabalhos, no entanto, não aprofunda a análise para averiguar a essência do processo.

A fim de superar essas limitações, propõe-se um escopo mais abrangente para esta pesquisa. Em outras palavras, que ela não se restrinja a locais e a portes específicos, mas antes contemple uma base amostral robusta, que aborde a essência e não apenas a forma do estabelecimento dos preços. A próxima seção relaciona os métodos empregados na busca de alcançar esse intento.

\section{MÉTODOS DA PESQUISA}

Esta pesquisa classifica-se como descritiva, tendo como objeto o estabelecimento de preços em empresas industriais localizadas no Brasil. Para viabilizar sua realização, empregaram-se métodos cujas características centrais são expostas nesta seção.

\subsection{Coleta de dados}

Os dados desta pesquisa foram coletados diretamente e, portanto, são classificados como primários. A coleta ocorreu mediante levantamento: uma estratégia de pesquisa apropriada quando se deseja responder a questões envolvendo análise de fatos e descrições (MARTINS; THEÓPHILO, 2009). O levantamento foi viabilizado com a aplicação de um questionário durante os meses de fevereiro a junho de 2016. Ligações telefônicas foram 
realizadas para identificar o contato dos potenciais respondentes, sendo o questionário encaminhado para o endereço eletrônico deles.

O questionário dividia-se em cinco blocos de perguntas fechadas, exceto aquelas referentes a nomes, e-mails, tempos exatos e principais produtos. Três diferentes tipos de perguntas fechadas foram colocados: dicotômico, de múltipla escolha e de escala Likert de cinco pontos.

\subsection{Perfil do respondente}

A decisão do perfil desejado para os participantes desta pesquisa subsidiou-se na análise das potenciais condições de oferecimento de informações relevantes e fidedignas sobre o estabelecimento dos preços. Abratt e Pitt (1985) identificaram que, tradicionalmente, os profissionais responsáveis por determinar os preços vêm dos departamentos de vendas e de marketing. Depois, aparecem os diretores gerais da empresa, seguidos por profissionais dos departamentos financeiros e de produção, respectivamente. Mais recentemente, Carricano, Trinquecoste e Mondejar (2010) citaram que grande parte das empresas já possui gestores de preços, cuja responsabilidade é estabelecer os preços oficiais.

Como não há estudos mostrando quais profissionais são responsáveis por estabelecer preços no Brasil, optou-se por definir, empresa a empresa, o participante da pesquisa. Especificamente, decidiu-se que os participantes seriam os profissionais com a melhor condição de oferecer informações relevantes e confiáveis sobre o tema estudado, independentemente da sua área de atuação na empresa.

\subsection{População e amostra da pesquisa}

Escolheu-se pesquisar exclusivamente empresas do setor industrial por três principais motivos. Primeiramente, o setor industrial tem condições expressivas de apresentar tanto empresas que oferecem produtos diferenciados quanto outras com produtos padronizados companhias, portanto, com e sem poder para formar preços. Em segundo lugar, as indústrias tendem a apresentar uma gama maior e mais complexa de possibilidades para a fórmula custos mais margem do que os setores de comércio e serviço, pois o custo fixo daquelas tende a ser maior do que o destas. Em terceiro lugar, os gestores de empresas industriais são aqueles 
que mais veem o estabelecimento dos preços como uma "dor de cabeça". Segundo Lancioni (2005), esse transtorno decorre da falta de entendimento sobre implicações das decisões de preços, não raramente complexas no contexto industrial.

Ademais, definiu-se a população da pesquisa considerando o argumento de que não é raro encontrar proprietários e/ou gestores de organizações de pequeno e médio porte que tomam decisões de preços de modo imprudente, ameaçando sua continuidade (CARSON et al., 1998). Diante disso, optou-se por restringir a população da pesquisa tanto aos profissionais de empresas de pequeno e médio porte notadamente reconhecidas, quanto àqueles de firmas de grande porte.

Para tanto, decidiu-se pela consulta a dois bancos de dados: da revista Exame Melhores e Maiores, que anualmente relaciona as maiores empresas brasileiras não financeiras de acordo com análises das demonstrações contábeis e de diversos indicadores; e da revista NEI (Noticiários de Equipamentos Industriais), que anualmente publica a edição especial Top Five, relacionando os cinco fornecedores industriais de diferentes categorias preferidos pelos leitores da revista, inclusive de pequeno e médio porte. As edições das publicações consideradas foram as dos anos 2014 e 2015.

Cumpre esclarecer que a revista Exame Melhores e Maiores relaciona não só as maiores empresas industriais, mas também as comerciais e de serviço. Contudo, como o setor investigado nesta pesquisa é o industrial, somente as maiores empresas de ramos industriais fazem parte da população. A revista NEI também não relaciona apenas empresas industriais, mas também distribuidores, representantes e prestadores de serviços, mas a população se restringiu aos fabricantes. A Tabela 2 relaciona a quantidade de empresas da população da pesquisa segregada pelo banco de dados originário.

Tabela 2 - População da pesquisa

\begin{tabular}{l|l}
\hline BANCO DE DADOS & NÚMERO TOTAL DE EMPRESAS \\
\hline Exame Melhores e Maiores (apenas) & 680 \\
\hline NEI (apenas) & 883 \\
\hline Exame Melhores e Maiores e NEI (ambas) & 53 \\
\hline TOTAL & $\mathbf{1 . 6 1 6}$ \\
\hline
\end{tabular}

Fonte: dados da pesquisa (2017).

A amostra utilizada nesta pesquisa classifica-se como não probabilística, já que sua obtenção ocorreu de forma não aleatória. Ela foi composta pelas empresas que espontaneamente aceitaram participar do estudo, especificamente, por profissionais de 380 
empresas que responderam ao instrumento de coleta de dados. Ao todo, receberam-se 395 respostas, no entanto 15 tiveram de ser eliminadas.

Vale mencionar que, conforme demonstra a Figura 1, a amostra contempla empresas de todas as regiões do Brasil e conta com representantes de 20 dos 26 estados brasileiros, bem como do Distrito Federal. A distribuição da amostra reflete a população das empresas industriais brasileiras, na qual São Paulo concentra mais empresas, seguido por estados do sul e por Minas Gerais.

Figura 1 - Localização da população e da amostra

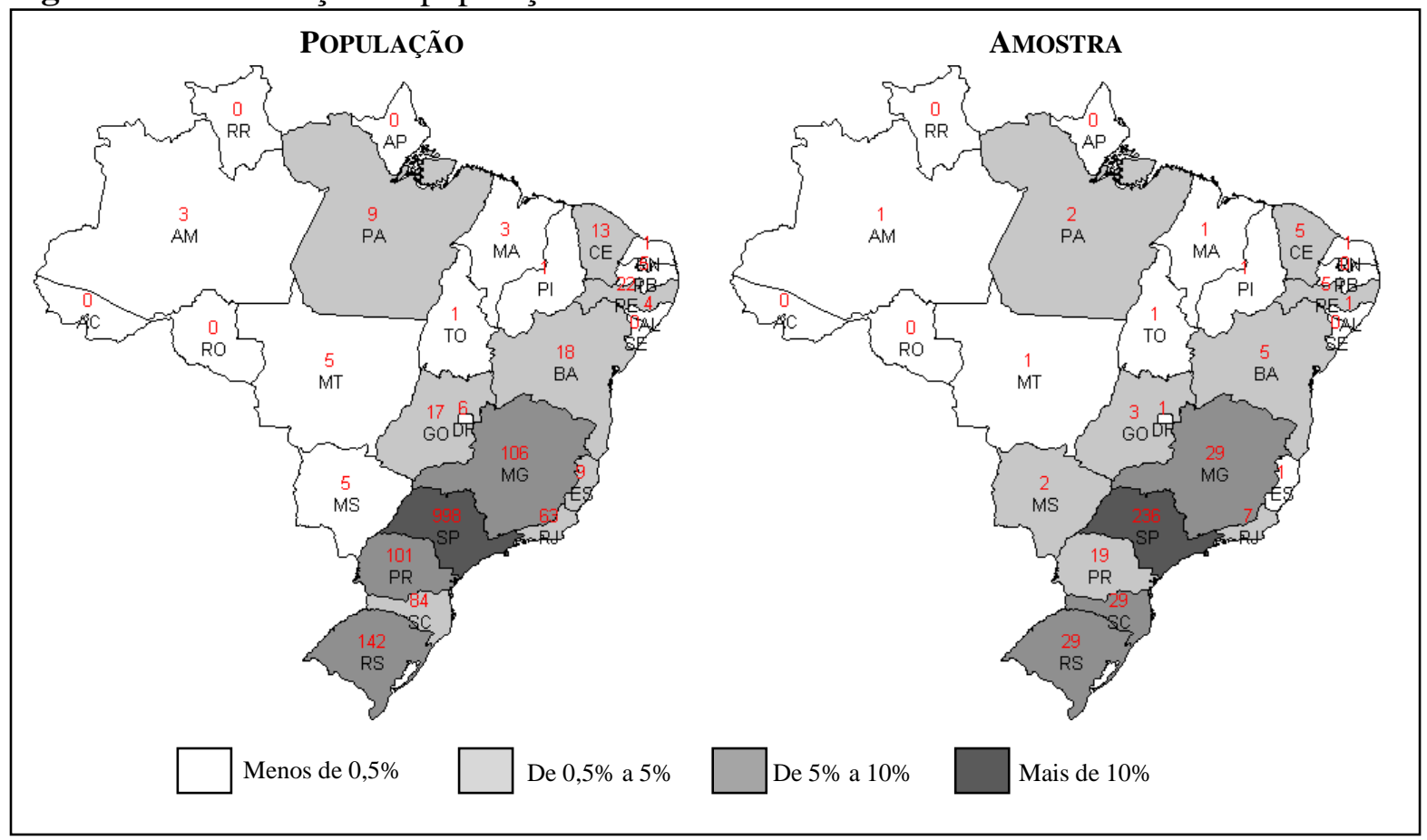

Fonte: elaborado com a utilização do Gismaps Viewer.

No que se refere ao porte das empresas da amostra, há presença de todos os tamanhos, embora se concentrem os portes maiores, como ilustra a Figura 2. Essa concentração, mais uma vez, espelha o modo como se compõe a população da pesquisa, considerando que se utilizou a base de dados da revista Exame Melhores e Maiores, que relaciona as maiores empresas brasileiras, em conjunto com a base da NEI. 
Figura 2 - Porte da amostra

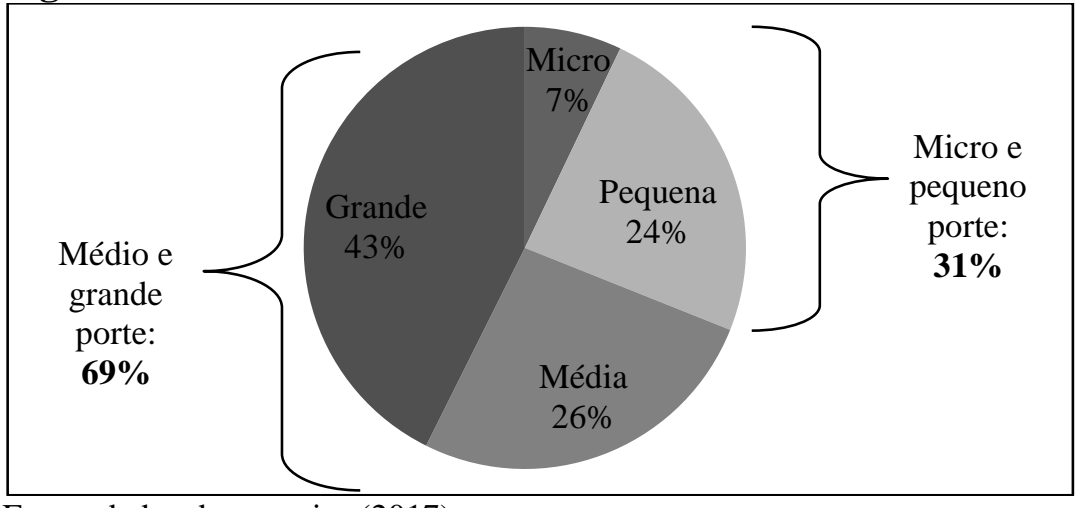

Fonte: dados da pesquisa (2017).

Finalmente, convém explicitar que participaram desta pesquisa empresas dos ambientes mais variados, mas, naturalmente, predominaram aquelas que ofertam produtos a outras, isto é, trata-se de firmas que atuam no ambiente B2B (business-to-business). Isso acontece porque todas as empresas relacionadas no banco de dados da NEI atuam no ambiente B2B e porque esse também é o ambiente predominante das empresas industriais do banco de dados da revista Exame Melhores e Maiores. A Tabela 3 evidencia a distribuição da amostra pelos segmentos de atuação.

Tabela 3 - Segmento da amostra

\begin{tabular}{l|l|l}
\hline SEGMENTO & QUANTIDADE & PERCENTUAL \\
\hline B2B (business-to-business) & 276 & $73 \%$ \\
\hline B2C (business-to-consumer) & 50 & $13 \%$ \\
\hline Commodities & 40 & $11 \%$ \\
\hline Engenharia e Construção & 14 & $4 \%$ \\
\hline
\end{tabular}

Fonte: dados da pesquisa (2017).

\section{APRESENTAÇÃO E DISCUSSÃO DOS RESULTADOS}

\subsection{Responsáveis pelo estabelecimento dos preços}

No Brasil, os principais responsáveis por definir preços são homens. Percebeu-se uma ampla desproporcionalidade na distribuição por gênero, já que $87 \%$ dos tomadores de decisões sobre os preços são homens (329), enquanto 13\% são mulheres (49). Em 2 empresas, há responsáveis homens e mulheres, pois mais de um profissional define o preço. A Figura 3 evidencia essa distribuição por gênero. 
Figura 2 - Gênero dos responsáveis

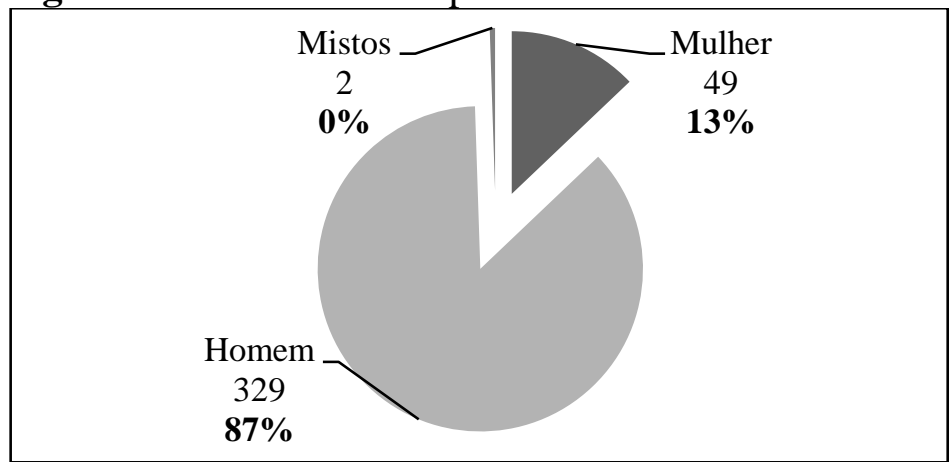

Fonte: dados da pesquisa (2017).

Outra característica dos responsáveis por estabelecer os preços no Brasil que merece ser salientada é a ocupação de função gerencial. Constatou-se que $87 \%$ dos profissionais que deliberam sobre os preços (330) são, em alguma extensão, gestores e que apenas 13\% (50) ocupam funções somente técnicas. A Tabela 4 demonstra detalhes dessa constatação e evidencia que, no geral, os preços são definidos pelos gerentes ou diretores. Em algumas empresas, a decisão é tomada diretamente pelos sócios e presidentes.

Tabela 4 - Função dos responsáveis

\begin{tabular}{l|l|l}
\hline FuNção & QUANTIDADE & PERCENTUAL \\
\hline Gerencial & $\mathbf{3 3 0}$ & $\mathbf{8 7 \%}$ \\
\hline Gerente/Diretor & 257 & $68 \%$ \\
\hline Supervisor/Coordenador & 64 & $17 \%$ \\
\hline Sócio/Vice-presidente/Presidente & 6 & $2 \%$ \\
\hline Chefe/Gestor & 3 & $1 \%$ \\
\hline Técnica & $\mathbf{5 0}$ & $\mathbf{1 3 \%}$ \\
\hline Analista/Assessor/Consultor & 33 & $9 \%$ \\
\hline Auxiliar/Assistente & 4 & $1 \%$ \\
\hline Contador/Controller/Orçamentista & 3 & $1 \%$ \\
\hline Vendedor/Executivo de vendas & 3 & $1 \%$ \\
\hline Engenheiro & 2 & $1 \%$ \\
\hline Outro & 5 & $1 \%$ \\
\hline Titro & &
\end{tabular}

Fonte: dados da pesquisa (2017).

Com relação ao departamento de atuação, pode-se observar na Figura 4 que, no Brasil, as deliberações de preços se concentram no setor de vendas, já que mais de um terço dos responsáveis (144) é vinculada a ele. Na sequência, aparecem os departamentos financeiros (finanças, custos, contabilidade etc.). Não é raro também encontrar profissionais responsáveis por definir os preços que, por serem gestores, atuam em mais de um departamento. As combinações mais comuns envolvem as áreas de vendas, marketing e preços. 
Figura 3 - Departamento dos responsáveis

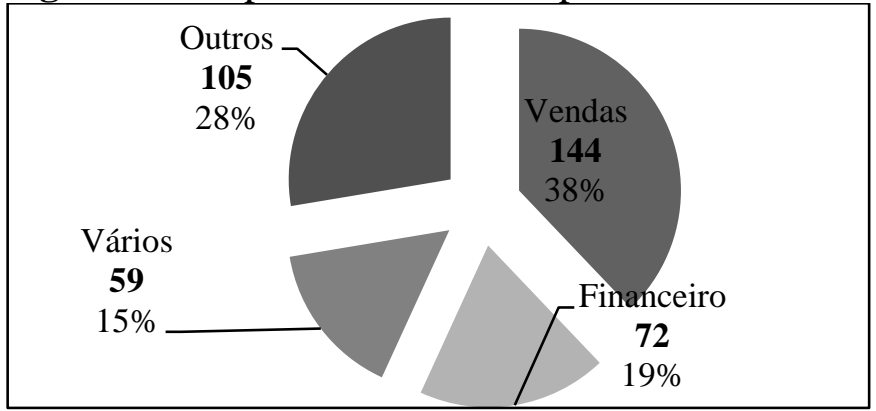

Fonte: dados da pesquisa (2017).

Finalmente, relativamente ao tempo de experiência dos profissionais em questão, constatou-se uma média de 12 anos e meio. Vale mencionar que o maior tempo de experiência no processo foi 50 anos, assinalado por dois profissionais, e que dois outros não responderam à pergunta. Nota-se, portanto, que os profissionais responsáveis pelas deliberações de preços são no geral portadores de ampla experiência com o tema.

\subsection{Enquadramento no estabelecimento dos preços}

Nem todas as empresas têm poder para formar preços. Esse poder está presente quando se oferecem produtos diferenciados, mas não no caso de produtos com versões iguais ou similares ofertadas pelos concorrentes (BANTERLE; CARRARESI; CAVALIERE, 2011). Por esse motivo, as empresas brasileiras devem ser divididas em formadoras e tomadoras de preços.

São tipicamente tomadoras de preços: aquelas que lidam com commodities (HARPER, 1966), as que oferecem produtos padronizados destinados ao consumo (MAXWELL, 1998) e aquelas de qualquer ambiente que, por não ofertarem produtos diferenciados, precisam colocar preços iguais ou similares aos concorrentes (HOFSTRAND, 2007). São formadoras de preços, por sua vez, as empresas que, por entregarem produtos diferenciados, têm condições de definir preços sem terem de seguir estritamente os concorrentes. A Tabela 5 evidencia a segregação das empresas brasileiras de acordo com seu enquadramento.

Tabela 5 - Enquadramento no estabelecimento dos preços

\begin{tabular}{l|l|l}
\hline ENQUADRAMENTO & QUANTIDADE & PERCENTUAL \\
\hline Formadoras de preços & 192 & $51 \%$ \\
\hline Tomadoras de preços & 188 & $49 \%$ \\
\hline TOTAL & $\mathbf{3 8 0}$ & $\mathbf{1 0 0 \%}$ \\
\hline
\end{tabular}

Fonte: dados da pesquisa (2017). 
Nota-se, portanto, uma distribuição balanceada entre empresas que formam e outras que tomam os preços. Cumpre porém ressaltar, como demonstrado na Tabela 6, que essa proporcionalidade não se encontra em todos os ambientes: em meio a produtos destinados ao mercado de consumo, à engenharia e, sobretudo, a commodities, há mais tomadores do que formadores de preços. Somente no ambiente B2B, há mais formadores do que tomadores de preços.

Tabela 6 - Enquadramento nos diferentes ambientes

\begin{tabular}{l|l|l|l}
\hline AMBIENTE & ENQUADRAMENTO & QUANTIDADE & PERCENTUAL \\
\hline \multirow{2}{*}{ B2B } & Formadoras de preços & 172 & $62 \%$ \\
\cline { 2 - 4 } & Tomadoras de preços & 104 & $38 \%$ \\
\hline \multirow{2}{*}{ B2C } & Formadoras de preços & 16 & $32 \%$ \\
\cline { 2 - 4 } & Tomadoras de preços & 34 & $68 \%$ \\
\hline \multirow{2}{*}{ Commodities } & Formadoras de preços & 0 & $0 \%$ \\
\cline { 2 - 4 } & Tomadoras de preços & 40 & $100 \%$ \\
\hline \multirow{2}{*}{ Engenharia } & Formadoras de preços & 4 & $29 \%$ \\
\cline { 2 - 4 } & Tomadoras de preços & 10 & $71 \%$ \\
\hline
\end{tabular}

Fonte: dados da pesquisa (2017).

\subsection{Informações usadas no estabelecimento dos preços}

Tanto nas empresas formadoras quanto nas tomadoras, as decisões de preços se pautam por informações. Na literatura, há o entendimento de que três são os principais tipos de informações usados ao definir preços: custos, concorrência e valor.

As informações de custos referem-se aos recursos consumidos para produzir determinado produto ou serviço. As informações da concorrência referem-se aos preços colocados no mercado pelos concorrentes. Por sua vez, as informações de valor referem-se aos benefícios e sacrifícios que os clientes enxergam nos produtos e ao quanto estão dispostos a pagar por eles (SHAPIRO; JACKSON, 1978; CUNNINGHAM; HORNBY, 1993; SMITH, 1995; SHIPLEY; JOBBER, 2001; INGENBLEEK et al., 2003; AVLONITIS; INDOUNAS, 2005; 2006; COLLINS; PARSA, 2006; HINTERHUBER, 2008; INDOUNAS, 2009; RAJU; ZHANG, 2010; HINTERHUBER; LIOZU, 2012; LIOZU et al., 2012; CALABRESE; FRANCESCO, 2014).

Nas indústrias brasileiras, observou-se que os custos se referem às informações usadas com mais intensidade no processo de definição dos preços. Em segundo lugar, aparecem as 
informações de valor nos formadores de preços e as informações da concorrência nos tomadores de preços, conforme demonstra a Tabela 7.

Tabela 7 - Informações usadas intensamente

\begin{tabular}{|c|c|c|c|c|c|}
\hline \multicolumn{3}{|c|}{ FORMADORES DE PREÇOS } & \multicolumn{3}{|c|}{ TOMADORES DE PREÇOS } \\
\hline INFORMAÇÃO & TIPO & QUANTIDADE & INFORMAÇÃO & TIPO & QUANTIDADE \\
\hline $\begin{array}{ll}\text { Impostos } & \text { sobre } \\
\text { vendas } & \\
\end{array}$ & Custos & 123 & \begin{tabular}{|ll}
$\begin{array}{l}\text { Impostos } \\
\text { vendas }\end{array}$ & sobre \\
\end{tabular} & Custos & 115 \\
\hline $\begin{array}{lr}\text { Margem } & \text { desejada } \\
\text { para os produtos } \\
\text { (margem } \\
\text { contribuição, de } \\
\text { lucro bruto ou de } \\
\text { lucro líquido) }\end{array}$ & Custos & 122 & $\begin{array}{l}\text { Custos } \\
\text { variáveis/diretos } \\
\text { dos produtos }\end{array}$ & Custos & 112 \\
\hline $\begin{array}{l}\text { Custos } \\
\text { variáveis/diretos } \\
\text { dos produtos }\end{array}$ & Custos & 108 & 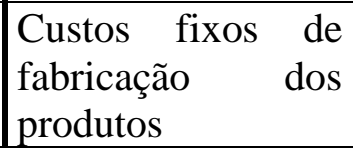 & Custos & 97 \\
\hline $\begin{array}{lr}\text { Custos fixos de } \\
\text { fabricação } \\
\text { produtos }\end{array}$ & Custos & 93 & 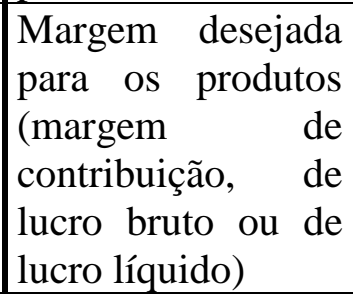 & Custos & 90 \\
\hline $\begin{array}{l}\text { Despesas } \\
\text { (administrativas, } \\
\text { comerciais } \\
\text { financeiras) }\end{array}$ & Custos & 75 & $\begin{array}{l}\text { Despesas } \\
\text { (administrativas, } \\
\text { comerciais } \\
\text { financeiras) }\end{array}$ & Custos & 82 \\
\hline 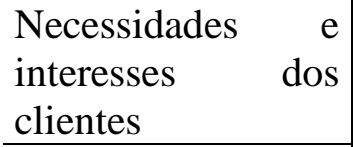 & Valor & 64 & $\begin{array}{l}\text { Nível de preço dos } \\
\text { concorrentes }\end{array}$ & Concorrência & 63 \\
\hline $\begin{array}{l}\text { Comparação entre } \\
\text { os benefícios } \\
\text { oferecidos e os } \\
\text { custos trazidos aos } \\
\text { clientes pelos } \\
\text { produtos }\end{array}$ & Valor & 56 & $\begin{array}{l}\text { Preços de produtos } \\
\text { concorrentes que } \\
\text { são iguais aos } \\
\text { nossos produtos }\end{array}$ & Concorrência & 54 \\
\hline $\begin{array}{l}\text { Percepções dos } \\
\text { clientes em relação } \\
\text { aos produtos }\end{array}$ & Valor & 52 & 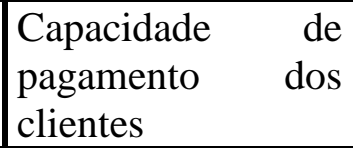 & Valor & 53 \\
\hline $\begin{array}{lr}\begin{array}{l}\text { Capacidade } \\
\text { pagamento } \\
\text { clientes }\end{array} & \text { dos } \\
\end{array}$ & Valor & 52 & \begin{tabular}{|lr}
$\begin{array}{l}\text { Necessidades } \\
\text { interesses } \\
\text { clientes }\end{array}$ & dos \\
\end{tabular} & Valor & 47 \\
\hline $\begin{array}{ll}\text { Valores } & \text { dos } \\
\text { investimentos } & \text { (em } \\
\text { maquinários, } \\
\text { instalações etc.) }\end{array}$ & Custos & 48 & $\begin{array}{l}\text { Estratégia de preço } \\
\text { dos concorrentes }\end{array}$ & Concorrência & 47 \\
\hline
\end{tabular}

Fonte: dados da pesquisa (2017). 
É importante destacar que os impostos sobre vendas, referentes a um dos vários custos de uma empresa, aparecem como a informação de uso mais intenso tanto nos formadores quanto nos tomadores de preços. Os estudos realizados nos demais países não tinham revelado tamanha utilização dessa informação, o que pode indicar tamanha elevação da carga tributária nacional, quando comparada aos outros países, que ela ultrapassa a importância dada às outras informações.

\subsection{Forma do estabelecimento dos preços}

Há mais de cinquenta anos, já se defendia que todas as empresas costumam empregar fórmulas matemáticas para incorporar as informações usadas no estabelecimento dos preços (EDWARDS, 1952). Avlonitis e Indounas (2006) mencionam que algumas fórmulas são simples, enquanto outras são sofisticadas. As fórmulas mais comuns, de acordo com Drury e Tayles (2006), são aquelas de custos mais margem. Segundo Avlonitis e Indounas (2005), destacam-se também fórmulas pautadas nos preços dos concorrentes:

- preço de venda $=$ preço dos concorrentes

- preço de venda $=$ preço dos concorrentes no mercado $+/$ - ajustes.

Conforme demonstra a Figura 5, realmente predomina no Brasil a fórmula custos mais margem, adotada por $284(265+19)$ empresas $(75 \%)$. Vale esclarecer que 19 dessas firmas adotam a fórmula em conjunto com outras (e.g., empresas ora usam fórmulas de custos mais margem, ora fórmulas de valor; ora empregam fórmulas de custos mais margem, ora fórmulas dos preços dos concorrentes etc.). Na sequência, aparecem as fórmulas pautadas: nos preços dos concorrentes (45), no valor (23), nos preços de mercado (15) e no uso mútuo de fórmulas que não incluem custos mais margem (7). Ainda há 2 empresas que definem os preços com base em tentativas e erros. 
Figura 4 - Principais formas de estabelecer os preços

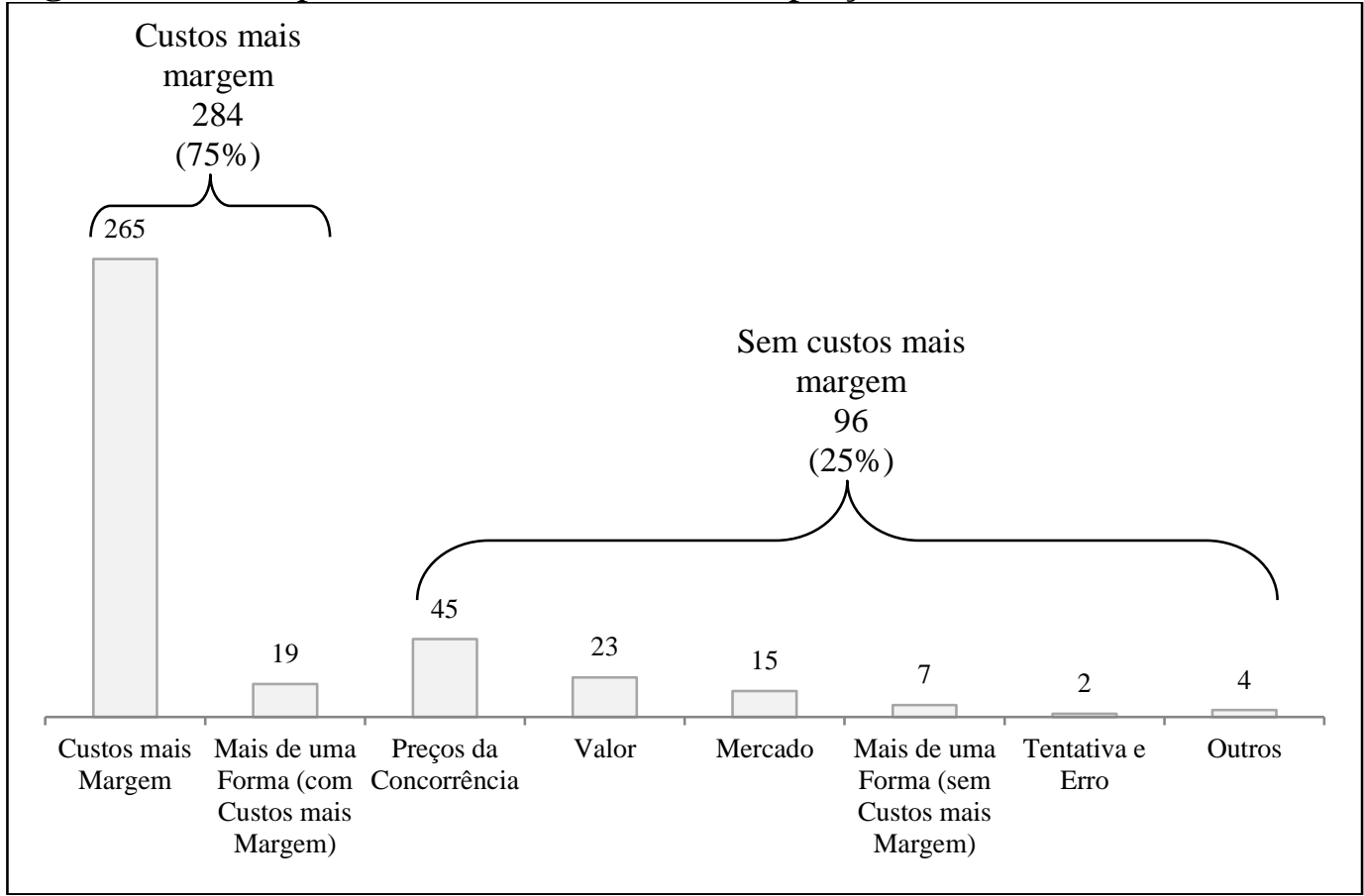

Fonte: dados da pesquisa (2017).

É relevante mencionar que, das 284 firmas em que os custos mais margem são a forma predominante de estabelecer preços, a maioria adere aos custos totais e à margem na forma percentual. Especificamente, $77 \%$ das firmas concordaram plenamente com a necessidade de todos os custos fixos de produção serem incluídos nas fórmulas de preços, e 70\% demonstraram clara concordância com a necessidade de todas as despesas fixas se incluírem nas fórmulas. Para $68 \%$ das firmas, era correto priorizar o uso de margens percentuais, em vez daquelas na forma unitária em reais.

\subsection{Essência do estabelecimento dos preços}

Não é porque as empresas, tomadoras e formadoras de preços, fazem uso da fórmula custos mais margem que elas estabelecem os preços unicamente com base nos custos. Nos tomadores de preços, a fórmula pode ser empregada para operacionalizar o estabelecimento dos preços, ainda que os finais precisem equiparar-se aos do mercado (LERE, 1979; DRURY; TAYLES, 2006). Para tanto, ou a margem já espelha os preços dos concorrentes possibilitando a determinação dos preços em uma única etapa -, ou a margem é arbitrária, mas com resultado alterado para equiparar-se aos preços dos concorrentes, o que deixa o processo com duas etapas. Nos formadores, o emprego da fórmula, além de viabilizar a 
colocação de preços que assegurem a cobertura dos custos e a geração do lucro desejado, pode operacionalizar o estabelecimento dos preços baseado no valor, por intermédio da margem (INDOUNAS, 2006).

Foxall $(1972 ; 1980)$ há tempos já reforçava essa ideia. O autor argumentava que as informações de custos dificilmente são as responsáveis isoladas pelo processo de determinar os preços. Ele defendia que as empresas, embora tomem a decisão aplicando uma fórmula que tenha os custos de base, geralmente usam margens flexíveis que permitem incorporar outras informações. Em outras palavras, pode-se endossar que a essência do processo, ou seja, o conjunto de informações realmente considerado como base para a definição final dos preços independe da fórmula usada.

Nesse sentido, cumpre avaliar quão rígidas, constantes e independentes são as margens somadas aos custos. Afinal, quando definidas isoladamente pelo departamento financeiro, elas não variam entre os produtos e entre os clientes, bem como independem de aspectos dos produtos e dos clientes, mas restringem o processo aos custos e inibem a incorporação de informações referentes à concorrência e ao valor. A Tabela 8 evidencia os principais atributos das margens adotadas pelas indústrias brasileiras.

Tabela 8 - Atributos das margens da fórmula custos mais margem

\begin{tabular}{|c|c|c|c|c|c|c|c|c|c|c|c|c|}
\hline \multirow[t]{2}{*}{$\begin{array}{l}\text { GRAU DE } \\
\text { CONCORDÂNCIA }\end{array}$} & \multicolumn{2}{|c|}{$\begin{array}{l}\text { MARGEM } \\
\text { DEFINIDA PELO } \\
\text { SETOR } \\
\text { FINANCEIRO }\end{array}$} & \multicolumn{2}{|c|}{$\begin{array}{l}\text { MARGEM } \\
\text { CONSTANTE } \\
\text { ENTRE } \\
\text { PRODUTOS }\end{array}$} & \multicolumn{2}{|c|}{$\begin{array}{l}\text { MARGEM } \\
\text { CONSTANTE } \\
\text { ENTRE } \\
\text { CLIENTES }\end{array}$} & \multicolumn{2}{|c|}{$\begin{array}{l}\text { MARGEM INDEPENDE } \\
\text { DAS } \\
\text { CARACTERÍSTICAS } \\
\text { ESPECÍFICAS DOS } \\
\text { PRODUTOS }\end{array}$} & \multicolumn{2}{|c|}{$\begin{array}{l}\text { MARGEM INDEPENDE } \\
\text { DAS } \\
\text { CARACTERÍSTICAS } \\
\text { ESPECÍFICAS DOS } \\
\text { CLIENTES }\end{array}$} & \multicolumn{2}{|c|}{$\begin{array}{l}\text { MARGEM INDEPENDE } \\
\text { DA IMPORTÂNCIA } \\
\text { CONSIDERADA PELOS } \\
\text { CLIENTES }\end{array}$} \\
\hline & QTDE. & $\%$ & QTDE. & $\%$ & QTDE. & $\%$ & QTDE. & $\%$ & QTDE. & $\%$ & QTDE. & $\%$ \\
\hline Neutralidade & 40 & $14 \%$ & 66 & $23 \%$ & 56 & $20 \%$ & 60 & $21 \%$ & 66 & $23 \%$ & 69 & $24 \%$ \\
\hline Concordância & 39 & $14 \%$ & 63 & $22 \%$ & 67 & $24 \%$ & 54 & $19 \%$ & 97 & $34 \%$ & 90 & $32 \%$ \\
\hline TOTAL & 284 & $100 \%$ & 284 & $100 \%$ & 284 & $100 \%$ & 284 & $100 \%$ & 284 & $100 \%$ & 284 & $100 \%$ \\
\hline
\end{tabular}

Fonte: dados da pesquisa (2017).

Pode-se perceber que, na maioria das empresas que definem os preços com base na fórmula custos mais margem, a margem não é definida somente pelo departamento financeiro, nem é constante entre os produtos e os clientes. Ademais, a maior parte das companhias busca incorporar, por intermédio da margem, características específicas dos produtos e dos clientes, assim como a importância considerada pelos clientes. 


\section{$5 \quad$ CONCLUSÕES}

A revisão dos estudos prévios sobre o estabelecimento dos preços no Brasil identificou limitações que prejudicavam o entendimento sobre o tema. Constatou-se que todas as pesquisas nacionais abordavam regiões geográficas bastante restritas, sobretudo sul e sudeste. Observou-se, ainda, que as amostras dos estudos eram pequenas, formadas principalmente por empresas de pequeno porte. Ademais, notou-se que os trabalhos não aprofundavam a investigação do assunto, restringindo-se à forma do processo.

Em contrapartida, expôs-se neste artigo uma pesquisa empírica atual com foco verdadeiramente nacional, isto é, com a participação de empresas de todas as regiões do Brasil. 380 empresas de variados portes, de 20 estados brasileiros e do Distrito Federal, participaram do estudo e viabilizaram a definição do panorama não só da forma, mas também da essência do estabelecimento dos preços no Brasil.

Primeiramente, observou-se que, neste país, as decisões de preços são tomadas, principalmente, por homens e por ocupantes de funções gerenciais. A maior parte desses profissionais advém do departamento de vendas.

Verificou-se também que a maior parte das empresas atuantes em segmentos do ambiente B2B é formadora de preços, diferentemente das atuantes em segmentos do ambiente B2C, de commodities e de engenharia, as quais são, em sua maioria, tomadoras de preços. As informações de custos são as informações usadas mais intensamente tanto nos formadores quanto nos tomadores de preços. Em segundo lugar, aparecem as informações de valor nos formadores de preços e as da concorrência nos tomadores de preços. Os impostos sobre as vendas - dentre os variados custos incorridos na venda dos produtos - são a informação mais utilizada.

A combinação custos mais margem configura a forma predominante do estabelecimento dos preços, seja em formadores ou em tomadores. Nessa combinação, há a ênfase na inclusão de todos os custos fixos de produção e de todas as despesas fixas, bem como no uso de margens percentuais.

Por fim, percebeu-se que a fórmula custos mais margem, apesar de ser a principal forma de definir os preços, não corresponde necessariamente à essência do processo. Afinal, a margem, além de não determinada apenas pelo departamento financeiro, não é constante entre os produtos e entre os clientes, mas busca incorporar de ambos características específicas. 
Ora, é praxe dos pesquisadores concluir que os preços se baseaiam nos custos simplesmente porque é empregada a combinação custos mais margem. Entretanto, demonstrou-se neste artigo que a forma nada diz sobre a essência do estabelecimento dos preços, pois é possível, sim, que preços definidos com base nos custos reflitam o valor ou os preços da concorrência por intermédio da margem.

Com esses achados, finalmente se consolidam, em um único estudo, as conclusões prévias e atualizadas - quer restritas, quer abrangentes - sobre o estabelecimento dos preços no Brasil. Espera-se que tal consolidação facilite o acesso dos pesquisadores e, assim, viabilize o avanço do conhecimento do tema. Do ponto de vista prático, espera-se que este estudo revele aos profissionais a realidade preponderante no Brasil, assim lhes facilitando discernir sobre como se estabelecem preços em outras entidades.

Ademais, neste trabalho, evidenciou-se aos profissionais que a simplicidade da combinação custos mais margem pode ser aproveitada sem deixar de refletir o valor oferecido aos clientes ou os preços dos concorrentes. A margem da fórmula pode ser o elemento conector dos custos ao valor ou ao preço da concorrência, desde que o processo não seja marcado pela essência custos. Quando a margem não é arbitrária e tampouco precisa ser única para todos os produtos e para todos os clientes, há flexibilidade na sua variação, o que permite incorporar o valor e os preços da concorrência.

Cumpre, contudo, esclarecer que este estudo, como as demais pesquisas científicas, possui limitações. A principal delas decorre do fato de nem todas as empresas industriais terem sido investigadas. Logo, os resultados apresentados não devem ser generalizados, pois demonstram a realidade apenas das empresas que compõem a amostra. A utilização de uma amostra não probabilística acentua essa limitação, embora seu caráter não aleatório e restritivo do alcance dos resultados consiga, de acordo com Castro (1977), fornecer informações extremamente importantes e úteis.

Outra limitação está relacionada ao instrumento de coleta de dados. Ainda que o questionário tenha sido pré-testado, não se pode deixar de advertir sobre o modo de os respondentes interpretarem as questões. As interpretações podem ser distintas por refletirem o discernimento que cada um possui sobre o que está sendo perguntado. Tal limitação é inerente à escolha do levantamento como estratégia de pesquisa. 
Finalmente, mais uma limitação decorre da demonstração do estabelecimento dos preços no momento em que a pesquisa foi realizada, ou seja, da característica temporal do estudo. Com o passar do tempo, a realidade pode ser modificada. 


\section{REFERÊNCIAS}

ABRATT, R.; PITT, L. F. Pricing practices in two industries. Industrial Marketing Management, v. 14, n. 4, p. 301-306, 1985.

ALMEIDA, L. B.; SANTOS, A. R. Práticas de contabilidade de custos: uma investigação nas indústrias paranaenses. Sociedade, Contabilidade e Gestão, v. 2, n. 1, p. 19-34, 2007.

ALVES, C. A.; VAROTTO, L. F.; GONÇALVES, M. N. Objetivos e métodos de preço no varejo: estudo na zona sul de São Paulo. RAE, v. 52, n. 6, p. 595-612, 2012.

AVLONITIS, G. J.; INDOUNAS, K. A. Pricing objectives and pricing methods in the service sector. Journal of Services Marketing, v. 19, n. 1, p. 47-57, 2005.

AVLONITIS, G. J.; INDOUNAS, K. A. How are prices set? An exploratory investigation in the Greek services sector. Journal of Product \& Brand Management, v. 15, n. 3, p. 203213, 2006.

BANTERLE, A.; CARRARESI, L.; CAVALIERE, A. What is the role of marketing capability to be a price maker? An empirical analysis in Italian food SMEs. Economia \& Diritto Agroalimentare, v. XVI, n. 2, p. 245-261, 2011.

BARBOSA, R. V. N. O emprego de informações de custos na formação de preços de indústrias brasileiras: uma pesquisa de campo. In: VIII CONGRESO DEL INSTITUTO INTERNACIONAL DE COSTOS. Anais... Punta del Este, Uruguay, Instituto Internacional de Costos, 2003.

BRAGA, A. X. V.; SOUZA, M. A. KRONBAUER, C.; BRAGA, D. P. G. Costs, prices and results' management: a study conducted in fruit canning companies located in Rio Grande do Sul state, Brazil. International Business Research, v. 5, n. 3, p. 58-70, 2012.

CALABRESE, A.; FRANCESCO, F. A pricing approach for service companies: service blueprint as a tool of demand-based pricing. Business Process Management Journal, v. 20, n. 6, p. 906-921, 2014.

CAlladO, A. L. C.; MACHADO, M. R.; CALlADO, A. A. C.; MACHADO, M. A. V.; ALMEIDA, M. A. Custos e formação de preços no agronegócio. Faces: Revista de Administração, v. 6, n. 1, p. 52-61, 2007. 
CANEVER, F. P.; LUNKES, R. L.; SCHNORRENBERGER, D.; GASPARETTO, V. Formação de preços: um estudo em empresas industriais de Santa Catarina. Revista de Contabilidade do Mestrado em Ciências Contábeis da UERJ, v. 17, n. 2, p. 14-27, 2012.

CARRICANO, M.; TRINQUECOSTE, J. F.; MONDEJAR, J. A. The rise of the pricing function: origins and perspectives. Journal of Product \& Brand Management, v. 19, n. 7, p. 468-476, 2010.

CARSON, D.; GILMORE, A.; CUMMINS, D.; O'DONNEL, A.; GRANT, K. Price setting in SMEs: some empirical findings. Journal of Product \& Brand Management, v. 7, n. 1, p. 74-86, 1998.

CASTRO, C. M. A prática da pesquisa. São Paulo: McGraw-Hill do Brasil, 1999.

COGAN. S.; CABRAL, I.; CASTRO, F. A. R.; BISPO, P. L. O processo de formação do preço de venda das micro e pequenas empresas em dois municípios do interior do Rio de Janeiro. In: XIV CONGRESSO BRASILEIRO DE CUSTOS. Anais... João Pessoa, PB, Associação Brasileira de Custos, 2007.

COLLINS, M.; PARSA, H. G. Pricing strategies to maximize revenues in the lodging industry. Hospitality Management, v. 25, n. 1, p. 91-107, 2006.

COORDENAÇÃO DE APERFEIÇOAMENTO DE PESSOAL DE NÍVEL SUPERIOR. Diretoria de Avaliação. Documento de Área, 2009. Disponível em: <http://www.capes.gov.br/images/stories/download/avaliacao/ADMIN17jun10.pdf>. Acesso em: 30 dez. 2015.

COORDENAÇÃO DE APERFEIÇOAMENTO DE PESSOAL DE NÍVEL SUPERIOR. Webqualis. Plataforma Sucupira, 2016. Disponível em <https://sucupira. capes.gov.br/sucupira/public/consultas/coleta/veiculoPublicacaoQualis/listaConsultaGeralPeri odicos. jsf>. Acesso em: 30 jan. 2016.

CUNNINGHAM, D.; HORNBY, W. Pricing decision in small firms: Theory and practice. Management Decision, v. 31, n. 7, p. 46-55, 1993.

DALLABONA, A. S.; MELZ, L. J.; SANTOS, J. S. C.; NUNES, E. S. Formação do preço de honorários contábeis em Tangará da Serra-MT: análise dos componentes do preço. Revista UNEMAT de Contabilidade, v. 2, n. 3, p. 7-24, 2013. 
DIAS, L. N.; CARVALHO, F. M.; COGAN, S. Formação do preço de venda: teoria versus prática em lojas do setor de vestuário. In: XIII CONGRESSO BRASILEIRO DE CUSTOS. Anais... Belo Horizonte, MG, Associação Brasileira de Custos 2006.

DRURY, C.; TAYLES, M. Profitability analysis in UK organizations: an exploratory study. The British Accounting Journal, v. 38, n. 4, p. 405-425, 2006.

EDWARDS, R. The pricing of manufactured products. Economica, v. 19, n. 75, p. 298-307, 1952.

FOXALL, G. R. A descriptive theory of pricing for marketing. European Journal of Marketing, v. 6, n. 3, p. 190-194, 1972.

FOXALL, G. R. The logic of price decision-making. Management Decision, v. 18, n. 5, p. 235- 245, 1980.

HALL, R. I.; HITCH, C. J. Price theory and business behaviour. Oxford Economic Papers, v. 2, p. 12-45, 1939.

HAMANN, E. V.; PEREIRA, E. M.; BARRETO JUNIOR, E. A. M.; NASCIMENTO JÚNIOR, E. R. N.; SILVA, B. F. Custos para tomada de decisão para agroindústrias familiares da região de Planaltina-DF. In: XVI CONGRESSO BRASILEIRO DE CUSTOS. Anais... Belo Horizonte, MG, Associação Brasileira de Custos, 2010.

HARPER, D. Price policy and procedure. New York: Harcourt, Brace \& World, 1966.

HINTERHUBER, A. Customer value-based pricing strategies: why companies resist. Journal of Business Strategy, v. 29, n. 4, p. 41-50, 2008.

HINTERHUBER, A.; LIOZU, S. M. Is it time to rethink your pricing strategy? MIT Sloan Management Review, v. 53, n. 4, p. 68-77, 2012.

HOFSTRAND, D. Commodities versus differentiated products, 2007. Disponível em: $<$ https://www.extension.iastate.edu/agdm/wholefarm/html/c5-203.html>. Acesso em: $02 \mathrm{dez}$. 2014.

INDOUNAS, K. A. Making effective pricing decisions. Business Horizons, v. 49, n. 5, p. 415-424, 2006. 
INDOUNAS, K. A. Successful industrial service pricing. Journal of Business \& Industrial Marketing, v. 24, n. 2, p. 86-97, 2009.

INGENBLEEK, P. T. M.; DEBRUYNE, M.; FRAMBACH, R. T.; VERHALLEN, T. M. M.. Successful new product pricing practices: a contingency approach. Marketing Letters, v. 14, n. 4, p. 289-305, 2003.

KRUGER, S. D.; MAZZIONI, S.; GLUSTAK, E.; ZANIN, A. A contabilidade como instrumento de gestão dos estabelecimentos rurais. REUNIR: Revista de Administração, Contabilidade e Sustentabilidade, v. 4, n. 2, p. 134-153, 2014.

LANCIONI, R. Pricing issues in industrial marketing. Industrial Marketing Management, v. 34, n. 2, p. 111-114, 2005.

LERE, J. C. What cost is right for pricing? The CPA Journal, v. 49, n. 7, p. 76-77, 1979.

LIMA, F. G.; FERRAREZI, M. A.; SMITH, M. S. J. Formação de preços à luz da teoria das restrições: um estudo aplicado às indústrias metalúrgicas da cidade de Franca. In: I CONGRESSO UFSC DE INICIAÇÃO CIENTÍFICA EM CONTABILIDADE. Anais... Florianópolis, SC, UFSC, 2007.

LIOZU, S. M.; HINTERHUBER, A.; BOLAND, R.; PERELLI, S. The conceptualization of value-based pricing in industrial firms. Journal of Revenue and Pricing Management, v. 11, n. 1, p. 12-34, 2012.

MACHADO, D. G.; FIORENTIN, M.; SCARPIN, J. E. Formação de preços: um estudo em empresas do setor metalúrgico do estado de Santa Catarina. In: XIII SEMINÁRIOS EM ADMINISTRAÇÃO. Anais... São Paulo, SP, USP, 2010.

MACHADO, D. G.; SOUZA, M. A. Análise das relações entre a gestão de custos e a gestão do preço de venda: um estudo das práticas adotadas por empresas industriais conserveiras no RS. Revista Universo Contábil, v. 2, n. 1, p. 43-60, 2006.

MACHADO, M. A. V.; MACHADO, M. R.; HOLANDA, F. M. A. Análise do processo de formação de preços do setor hoteleiro da cidade de João Pessoa/PB: um estudo exploratório. In: XXX ENCONTRO DA ANPAD. Anais... Salvador, BA, ANPAD, 2006.

MARTINS, G.; THEÓPHILO, C. R. Metodologia da investigação científica para ciências sociais aplicadas. 2. ed. São Paulo: Atlas, 2009. 
MAXWELL, S. Pricing education in the United States of America: responding to the needs of business. Journal of Product \& Brand Management, v. 7, n. 4, p. 336-341, 1998.

MELLO, E. E. A política de preços na indústria de produtos alimentares. Economia e Desenvolvimento, v. 12, p. 19-47, 2000.

NAKAGAWA, F. Brasil cai para a posição de $9^{\mathbf{a}}$ economia do mundo [Versão eletrônica]. 2016. Exame.com. Disponível em: <http://exame. abril.com.br/economia/pib-em-dolar-cai25-e-brasil-cai-para a posicao-de-9a-economia-do-mundo/>. Acesso em: 18 nov. 2016.

QUEIROZ, L. L.; CONCEIÇÃO, I. E. P.; SILVA, J. F. B. A.; SANTOS, S. M.; CABRAL, A. C. A.; PESSOA, M. N. M. Estratégias de determinação de preços em microempresas no setor de artigos turísticos: um estudo comparativo entre Fortaleza e Mindelo. In: XX CONGRESSO BRASILEIRO DE CUSTOS. Anais... Uberlândia, MG, Associação Brasileira de Custos, 2013.

RAJU, J.; ZHANG, Z. J. Smart pricing: how Google, Priceline, and leading business use pricing innovation for profitability. Upper Saddle River (NJ): Pearson Education, 2010.

ROCHA, L. F.; LEAL, E. A. Gestão de preços: um estudo em pequenas empresas participantes do programa Empreender - Uberlândia-MG. Revista de Auditoria, Governança e Contabilidade, v. 3, n. 6, p. 61-77, 2015.

ROSADAS, L. A. S.; MACEDO, M. A. S. Formação do preço de venda: uma análise do setor de material de construção. In: XI CONGRESSO BRASILEIRO DE CUSTOS. Anais... Porto Seguro, BA, Associação Brasileira de Custos, 2004.

SHAPIRO, B. P.; JACKSON, B. B. Industrial pricing to meet customer needs. Harvard Business Review, v. 56, n. 6, p. 119-127, 1978.

SHIPLEY, D. D.; JOBBER, D. Integrative pricing via the pricing wheel. Industrial Marketing Management, v. 30, n. 3, p. 301-314, 2001.

SILVA, L. P.; SANTOS, R. V. Formação do preço e do lucro em indústrias exportadoras de equipamentos médico-hospitalares e odontológicos. In: XII CONGRESSO BRASILEIRO DE CUSTOS. Anais... Florianópolis, SC, Associação Brasileira de Custos, 2005.

SMITH, G. E. Managerial pricing orientation: the process of making pricing decisions. Pricing Strategy \& Practice, v. 3, n. 3, p. 28-39, 1995. 